\title{
SHIP MOTIONS IN SHALLOW WATER AS THE BASE FOR A PROBABILISTIC APPROACH POLICY
}

\author{
Marc Vantorre \\ Ghent University \\ Maritime Technology Division \\ Technologiepark 904 \\ B9052 Gent, Belgium \\ marc.vantorre@ugent.be
}

\author{
Jan Richter \\ Ghent University \\ Division of Maritime Technology
}

\author{
Erik Laforce \\ Flemish Government \\ Flanders Hydraulics Research \\ Berchemlei 115 \\ B2140 Antwerpen, Belgium
}

\author{
Katrien Eloot \\ Flemish Government \\ Flanders Hydraulics Research \\ \& \\ Ghent University \\ Maritime Technology Division
}

\author{
Evert Lataire \\ Ghent University \\ Division of Maritime Technology
}

\begin{abstract}
A calculation tool has been developed for determining tidal windows for deep-drafted ships approaching and leaving the Belgian harbors according to probabilistic criteria. The calculations are based on a database containing response functions for the vertical motions in waves and squat data for a selection of representative ships. The database contains both results of model tests carried out in the Towing tank for maneuvers in shallow water - co-operation Flanders Hydraulics Research \& Ghent University in Antwerp (Belgium), as well as calculated values. During the experiments, draft, trim, under keel clearance (7 to $20 \%$ of draft) and speed have been varied. The tests were performed in regular waves with lengths which are small compared to ship length, and in wave spectra that are typical for the Belgian coastal area.

For given input data (ship characteristics, speed, tide, directional wave spectra, bottom, trajectory, current, departure time), the tool calculates the probability of bottom touch during the transit, so that a tidal window can be determined. Other restrictions, such as penetration into fluid mud layers and current, are taken into account as well.
\end{abstract}

\section{INTRODUCTION}

Deep-drafted ships approaching the Belgian harbors of Antwerp, Zeebrugge, and Ghent, and the Dutch harbor of Flushing-Terneuzen are subject to tidal windows, determined in such a way that a prescribed gross under keel clearance is guaranteed during the passage through the access channels. The Scheur West channel links the deeper Wandelaar area in the southern North Sea via the Pas van het Zand to the port of Zeebrugge, and via the Scheur East and Wielingen channels to the mouth of the river West Scheldt near Flushing. The navigation channel of the West Scheldt leads to Terneuzen, where a lock system gives access to the sea canal to Ghent, and further to the port of Antwerp, where deep-drafted ships can either berth on one of the river terminals or the tidal Deurganck Dock, or enter the Zandvliet or Berendrecht Locks.

At present, the determination of tidal windows is based on a minimum value for the gross under keel clearance, expressed as a percentage of the ship's draft. This minimum value depends on the channel, taking account of the wave climate and the ships' speed range (Fig. 1):

- $15.0 \%$ for Scheur West, Scheur East and Wielingen;

- $12.5 \%$ for Pas van het Zand and West Scheldt (Dutch part);

- $10.0 \%$ for the Scheldt river on Belgian territory and for the Zeebrugge outer harbor area, i.e. within the breakwaters;

- $1.0 \mathrm{~m}$ for the Sea Canal from Terneuzen to Ghent.

In addition, ships do not enter the harbor of Zeebrugge if the cross current in the approach channel exceeds 2 knots, or if the keel penetrates more than $7 \%$ of the draft into the fluid mud.

Obviously, the present access policy accounts for water level fluctuations due to tidal action and for the ship's draft, but does not make any distinction regarding other ship characteristics, weather conditions or wave climate. An optimization of the access policy appears to be feasible, provided that a reliable estimation of the ships' vertical motions due to the (actual and expected) waves and to squat effects is 
available, so that the probability of bottom touch during the passage can be assessed.

For this reason, a database of ship response functions has been generated, based on both experimental and computational results. Four ship types were selected, two full and two slender hull forms, and tested intensively in the shallow water towing tank at Flanders Hydraulics Research; in 2008, additional tests are performed with a model of a last generation container vessel. Draft, trim, under keel clearance (7 to $20 \%$ of draft) and speed have been varied. The tests were performed in regular waves with lengths which are small compared to ship length, and in wave spectra that are typical for the Belgian coastal area. The tests were carried out in head waves $(180 \pm 10 \mathrm{deg})$ and in following waves $(0 \pm 10 \mathrm{deg})$.

The resulting database can be considered as unique, not only because of the response of ships in waves in (very) shallow water conditions, but also from the point of view of squat. These data were used to validate two ship motion calculation programs, so that missing conditions in the database could be extrapolated.

Based on this database, a probabilistic admittance policy tool has been developed. For given input data (ship characteristics, speed, tide, directional wave spectra, bottom, trajectory, current, departure time), the tool calculates the probability of bottom touch during the transit, so that a tidal window can be determined. Other restrictions, such as penetration into fluid mud layers and current, are taken into account as well.

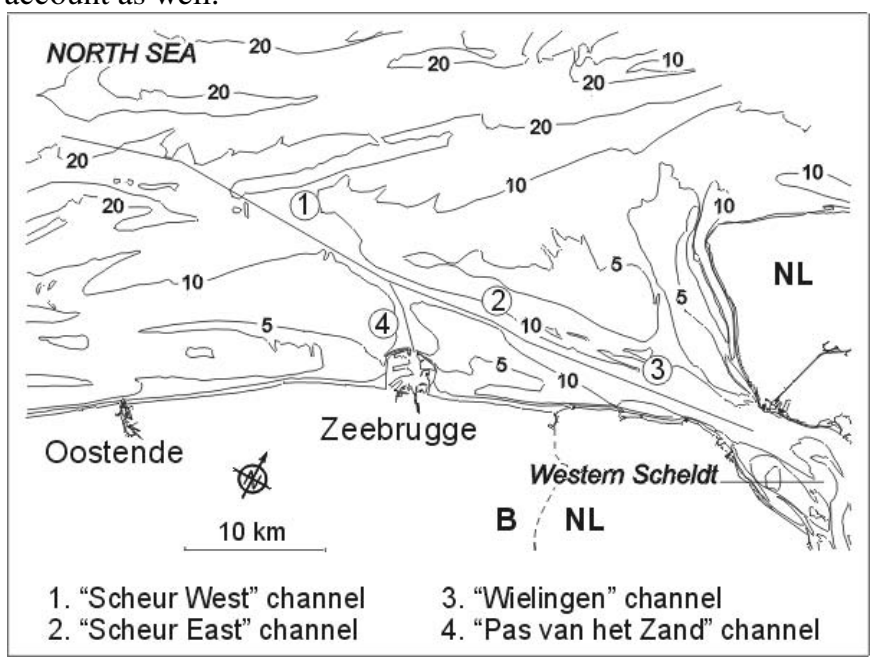

Fig. 1. Access channels to the Western Scheldt and Zeebrugge.

The paper intends to give an overview of the experimental results, to comment on the comparison between experimental and numerical results, to describe the philosophy of the calculation procedure, and to illustrate the methodology with some examples. Special attention will be paid to probabilistic aspects that are usually not taken into account, such as the uncertainty of the wave climate and tide forecast.

\section{NOMENCLATURE}

$\mathrm{A}_{\mathrm{C}} \quad$ Equivalent channel cross section $\left[\mathrm{m}^{2}\right]$

$\mathrm{A}_{\mathrm{S}} \quad$ Midship section $\left[\mathrm{m}^{2}\right]$

B Ship's beam $[\mathrm{m}]$

$\mathrm{C}_{\mathrm{B}} \quad$ Block coefficient [-]

$\mathrm{Fr}_{\mathrm{h}} \quad$ Depth based Froude number, see (2) [-]

$\mathrm{Fr}_{\mathrm{h}}^{\prime} \quad$ Alternative depth based Froude number, see (4) [-]

$\mathrm{g} \quad$ Acceleration of gravity $\left[\mathrm{ms}^{-2}\right]$

$\mathrm{h} \quad$ Water depth $[\mathrm{m}]$

$\mathrm{h}_{\mathrm{j}} \quad$ Water depth at sub-trajectory i [m]

$\mathrm{k}_{\mathrm{m}} \quad$ Blockage dependent factor influencing critical speed in confined channels

$\mathrm{k}_{\mathrm{s}} \quad$ Ship dependent factor influencing critical speed in confined channels

$\mathrm{L}_{\mathrm{OA}} \quad$ Length over all [m]

$\mathrm{L}_{\mathrm{PP}} \quad$ Length between perpendiculars $[\mathrm{m}]$

$\mathrm{L}_{\mathrm{j}} \quad$ Length of sub-trajectory $\mathrm{i}[\mathrm{m}]$

m Mass [kg]

$\mathrm{m}_{0, \mathrm{Z}_{\ell}} \quad 0^{\text {th }}$ moment of response spectrum of vertical motion of critical point $\ell\left[\mathrm{m}^{2}\right]$

$\mathrm{m}_{2, \mathrm{Z}_{\ell}} \quad 2^{\text {nd }}$ moment of response spectrum of vertical motion of critical point $\ell\left[\mathrm{m}^{2} \mathrm{~s}^{-2}\right]$

N Number of critical points [-]

P Probability of bottom touch over trajectory [-]

$P_{j} \quad$ Probability of bottom touch in sub-trajectory $j[-]$

$\mathrm{P}_{\mathrm{G}}(\mathrm{x} ; \mu ; \sigma)$ Cumulative normal distribution of argument $\mathrm{x}$, with average $\mu$ and standard deviation $\sigma$

$\mathrm{p}_{\mathrm{G}}(\mathrm{x} ; \mu ; \sigma)$ Normal distribution of argument $\mathrm{x}$, with average $\mu$ and standard deviation $\sigma$

$\mathrm{p}_{\mathrm{R}}\left(\mathrm{x} ; \mathrm{x}_{\mathrm{s}}\right) \quad$ Rayleigh distribution of argument $\mathrm{x}$, with significant value $\mathrm{x}_{\mathrm{s}}$

$\mathrm{p}_{\mathrm{RG}}\left(\mathrm{x} ; \mathrm{x}_{\mathrm{s}} ; \sigma\right)$ Distribution of $\mathrm{x}$ for based on a Rayleigh distribution with significant value $\mathrm{x}_{\mathrm{s}}$ that is normally distributed with standard deviation $\sigma$

$P^{(1)} \quad$ Probability of bottom touch for critical point $\ell$ in sub-

$\mathrm{P}_{\mathrm{j}, \ell} \quad$ trajectory $\mathrm{j}$ during one oscillatory cycle [-]

$P_{j, \ell} \quad$ Probability of bottom touch for critical point $\ell$ in subtrajectory $\mathrm{j}[-]$

$\mathrm{S} \quad$ Blockage factor, see Fig. $3[-]$

$\mathrm{S}_{\zeta}(\omega) \quad$ Spectral density of wave as a function of frequency $\left[\mathrm{m}^{2} \mathrm{~s}\right]$

$S_{\zeta}(\omega ; \mu) \quad$ Spectral density of wave as a function of frequency and incident angle $\left[\mathrm{m}^{2} \mathrm{~s}\right]$

$\mathrm{S}_{\mathrm{Z}_{\ell}}(\omega ; \mu)$ Spectral density of vertical motion of critical point $\ell$ as a function of frequency and incident angle $\left[\mathrm{m}^{2} \mathrm{~s}\right]$

$\mathrm{T} \quad$ Ship's draft [m]

$\mathrm{T}_{\mathrm{h}} \quad$ Tuck parameter, see (1) [-]

$\mathrm{T}_{\mathrm{h}}^{\prime} \quad$ Modified Tuck parameter, see (3) [-]

u Ship's forward speed component $[\mathrm{m} / \mathrm{s}]$

$\mathrm{UKC}_{\mathrm{j}, \ell} \quad$ net under keel clearance for point $\ell$ in sub-trajectory $\mathrm{j}$

$\mathrm{V} \quad$ Ship's speed $[\mathrm{m} / \mathrm{s} ; \mathrm{knots}]$

$\mathrm{Y}_{\mathrm{Z}_{\ell} \zeta}(\omega ; \mu)$ Amplitude response function for wave-induced vertical motion of critical point $\ell$ as a function of wave frequency and direction [-]

$\overline{\mathrm{Z}_{\ell}} \quad$ Sinkage due to squat of critical point $\ell[\mathrm{m}]$

$\mathrm{Z}_{\mathrm{s}, \ell} \quad$ Significant value of vertical motion of critical point $\ell$ [m]

$\mu \quad$ Incident wave angle [deg]

$\zeta \quad$ Wave elevation [m]

$\omega \quad$ Wave frequency $\left[\mathrm{rad} \mathrm{s}^{-1}\right]$ 


\section{GENERAL STRUCTURE OF THE CALCULATION TOOL}

The calculation tool, named ProToel, is developed in an object oriented programming environment, making use of Java.

The following information is required to run the program:

- a database of available ships;

- a database of trajectory points;

- a database of trajectories, consisting of a sequence of trajectory points;

- recent bottom data for each of the trajectory points;

- forecasts of hydro-meteorological data for a number of socalled reference locations, as a function of time: tidal elevation, directional wave spectra, current speed and direction, water density.

The application user has to introduce the following input data by means of a graphical user interface (gui) or a task list (spreadsheet file):

- $\quad$ Ship data: the user specifies ship type (full or slender) and main dimensions (length, beam), or selects a particular ship of the data base;

- Loading condition: draft fore, draft aft, GM;

- Route data: trajectory, planned starting time, number of voyages to be calculated before and after the planned starting time with a given time interval between the voyages;

- Ship speed (over ground or through the water) in each trajectory point.

A report, generated as a spreadsheet file, allows a detailed assessment of each calculated voyage. If the consecutive voyages cover a complete tidal cycle, an overview of the tidal window is presented in a tabular summary report. The limits of the tidal window for the considered ship are determined by means of a number of trajectory point dependent criteria:

- Probability of bottom touch;

- Gross under keel clearance referred to the nautical bottom;

- Penetration into fluid mud layers;

- Cross current speed.

\section{HYDRO-METEO INPUT DATA}

The calculation tool requires the following hydrological and meteorological information to be available for a number of selected reference points. Each trajectory point is linked to one reference point.

- Tidal data (water levels) as a function of time;

- Wave conditions for a number of discrete time steps: spectral energy density, average and standard deviation of angle of propagation;

- Current speed and direction as a function of time;

- Water density as a function of time.

If ProToel is used as a planning tool, these data are based on forecasts. Obviously, the quality of the output is directly related to the reliability of these forecasts. For tide forecasts, it is of great importance that the entire tidal curve is predicted well, not only the high and low tides. Although hydraulic models for tide forecasting also produce current predictions, the latter are mostly less reliable on a detailed local scale. Wave forecasts containing the detailed required information are not always available; as an example, prediction models seldom generate directional spreading data. In order to take account of the uncertainty of the forecasted data, a standard deviation on the water level, the significant wave height and the current speed can be introduced.

For each trajectory point, the bottom level needs to be defined. Guaranteed or intervention levels can be used for this purpose, but if hydrographical soundings are performed frequently, it is more appropriate to make use of the actual level. For each trajectory point, a depth value and a standard deviation can be given; mostly, the minimum depth over $80 \%$ of the channel width is taken into account, while the standard deviation is related to sedimentation and dredging allowances.

\section{SHIP DATA BASE}

\section{Overview}

In order to calculate the probability of bottom touch during a particular voyage, the program requires information about the vertical motion of the ships in the database:

- Squat data: average sinkage and trim;

- Dynamic response characteristics (motion amplitude relative to wave amplitude and phase lag as a function of wave pulsation and angle of incidence of wave) for the vertical motions (heave, pitch, roll) due to waves;

- Correction factors for response in irregular seaways.

The database is based on results of model experiments and numerical calculations.

The model tests were carried out in 1996-2000 in the Towing tank for maneuvers in shallow water (co-operation Flanders Hydraulics Research - Ghent University) in Antwerp, Belgium, with four ship models: two normative ships (D, E) and two critical ships (F, G), see Table 1, [1]. The normative ships, a slender ship type (model D, container carrier) and a full one (model E, tanker / bulk carrier) were, in an early stage of the research project, expected to be the largest ones in their category expected to frequent the harbors of Antwerp, Ghent and Zeebrugge in long term. Taking account of the wave characteristics in the southern part of the North Sea, it can be expected that these normative ships will not be subject to the largest motions; deep-drafted ships with smaller horizontal dimensions may have a larger probability of bottom touch. For this critical category, two ship models - a slender (model F, panamax container carrier) and a full ship (model G, panamax bulk carrier) - were selected as well. 


\begin{tabular}{|c|c|c|c|c|c|c|c|c|c|c|c|c|c|}
\hline & \multicolumn{12}{|c|}{ Length over all [m] } \\
\hline & & 180.0 & 200.0 & 220.0 & 240.0 & -260.0 & 290.0 & -300.0 & 320.0 & 340.0 & 360.0 & 380.0 & 400.0 \\
\hline & & 199.9 & 219.9 & 239.9 & 259.9 & 279.9 & 299.9 & 319.9 & 339.9 & 359.9 & 379.9 & 399.9 & 419.9 \\
\hline & $30.0-32.9$ & $\overline{G 100}$ & $\mathrm{~F} 100$ & & D080 & & & & & & & & \\
\hline & $33.0-35.9$ & G105 & F105 & F110 & & D085 & & & & & & & \\
\hline & $36.0-38.9$ & G110 & G115 & F115 & F120 & D090 & D095 & & & & & & \\
\hline & $39.0-41.9$ & & G120 & G125 & & F130 & W072 & D100 & & & & & \\
\hline & $42.0-44.9$ & & & & & E080 & F140 & W078 & D105 & D110 & & & \\
\hline $\boldsymbol{\xi}$ & $45.0-47.9$ & & & & & E085 & E090 & W080 & W085 & D115 & D118 & & \\
\hline 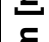 & $48.0-50.9$ & & & & & & & E095 & & W090 & D120 & D125 & \\
\hline & $51.0-53.9$ & & & & & & & & E100 & & W095 & & \\
\hline & $54.0-56.9$ & & & & & & & & & & & W100 & \\
\hline & & & $\begin{array}{l}\text { Sourc } \\
\text { Souro }\end{array}$ & $\begin{array}{l}\text { Sont } \\
\text { Bulk }\end{array}$ & ersh & & & & & $\begin{array}{l}\text { ersh } \\
\text { rier }\end{array}$ & & & \\
\hline
\end{tabular}

Figure 2. Combinations of ship length and beam covered by the database. The code refers to ship model (D, E, F, G, W) and scale factor (\%).

Due to the recent spectacular increase of the capacity of container vessels, these models are no longer representative for the ships calling at the Belgian ports. For example, in September 2007, Elly Maersk, with a length of $398 \mathrm{~m}$ and 56.4 $\mathrm{m}$ beam, berthed in the port of Zeebrugge. For this reason, it was decided to extend the database and perform model tests and calculations with a last generation container carrier (W). The model tests are planned for the first half of 2008.

By adapting the scale factor, a series of ships can be derived from each of the five parent scale models. In this way, the complete range of interest of length-beam ratios is covered by the investigated ship models, see Fig. 2.

\section{Squat Data}

Due to a ship's forward speed, the pressure and, hence, the water level around the ship is lowered, causing a sinkage and a change of trim. This phenomenon is especially significant in restricted waters, where the influence of squat increases.

Initially, the database contained a tabular relationship of mean sinkage and dynamic trim as a function of the speed through the water for each of the combinations ship type - scale factor - water depth - draft. Taking account of the bathymetry of the dredged channels in the North Sea, the effect of the lateral boundaries of the waterways due to blockage could be neglected. In order to be able to extend the calculation tool with trajectories in more confined waters such as rivers and canals, where blockage may be of interest, an alternative calculation method for squat of container vessels has been developed, based on various series of model tests. Principally, the formulation is based on the widely used Tuck parameter $T_{h}$ :

$$
\mathrm{T}_{\mathrm{h}}=\frac{\mathrm{Fr}_{\mathrm{h}}^{2}}{\sqrt{1-\mathrm{Fr}_{\mathrm{h}}^{2}}}
$$

$$
\mathrm{Fr}_{\mathrm{h}}=\frac{\mathrm{u}}{\sqrt{\mathrm{g} \cdot \mathrm{h}}}
$$

However, the present method makes use of an alternative Tuck parameter that takes account of the effect induced by the lateral boundaries of the waterway. (1) is replaced by:

$$
\mathrm{T}_{\mathrm{h}}^{\prime}=\frac{\mathrm{Fr}_{\mathrm{h}}^{\prime 2}}{\sqrt{1-\mathrm{Fr}_{\mathrm{h}}^{\prime 2}}}
$$

with

$$
\mathrm{Fr}_{\mathrm{h}}^{\prime}=\frac{\mathrm{u}}{\sqrt{\mathrm{k}_{\mathrm{m}} \mathrm{k}_{\mathrm{s}} \mathrm{gh}}}
$$

$\mathrm{k}_{\mathrm{m}}$ is a blockage dependent factor:

$$
\mathrm{k}_{\mathrm{m}}=\left[2 \cdot \sin \left(\frac{\operatorname{Arcsin}(1-\mathrm{m})}{3}\right)\right]^{3}
$$

$\mathrm{m}$ denotes an equivalent blockage factor, defined in Fig. 3. It should be noted that Schijf's limiting Froude Number [2] equals $\mathrm{k}_{\mathrm{m}} \mathrm{Fr}_{\mathrm{h}} . \mathrm{k}_{\mathrm{s}}$ is a ship dependent factor that increases with the draft.

The importance of squat and its dependence on ship characteristics is illustrated in Figs. 4-5, [3]. In particular, Fig. 4 shows that an increase of draft may lead to a decrease of squat, for equal values of the under keel clearance expressed as a fraction of the draft. This can be explained by the fact that, under these circumstances, an increased draft implies an increased water depth and, therefore, a reduced Froude depth number $\mathrm{Fr}_{\mathrm{h}}$ for the same speed. In addition, a variation of the dynamic trim (bow- or stern-heavy) is noticed during the experiments depending on the load condition or draft.

with 


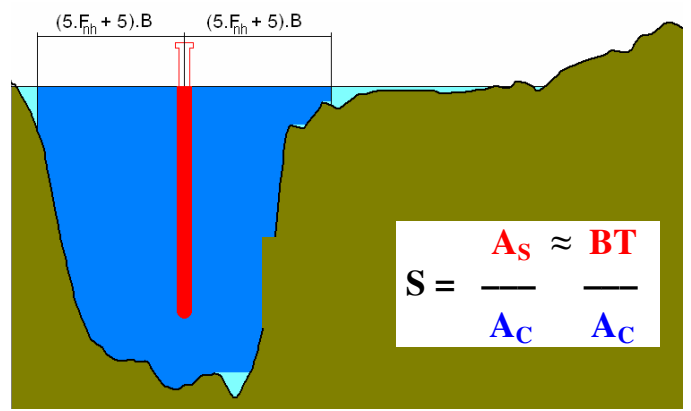

Fig. 3. Blockage definition for squat calculation.

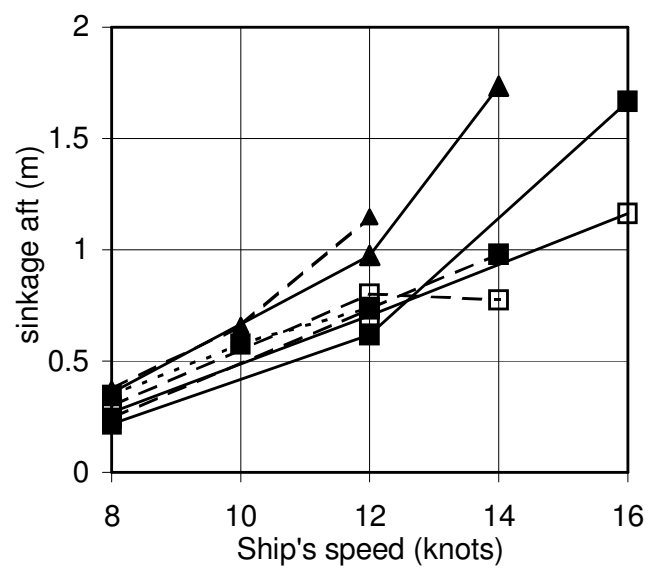

$\longrightarrow-\mathrm{h}=18.0 \mathrm{~m} ; \mathrm{T}=15.0 \mathrm{~m} ; \mathrm{TA}-\mathrm{TV}=0.0 \mathrm{~m}$ - $-\mathrm{h}=17.0 \mathrm{~m} ; \mathrm{T}=15.0 \mathrm{~m} ; \mathrm{TA}-\mathrm{TV}=0.0 \mathrm{~m}$ $\cdots-\mathrm{h}=16.0 \mathrm{~m} ; \mathrm{T}=15.0 \mathrm{~m} ; \mathrm{TA}-\mathrm{TV}=0.0 \mathrm{~m}$ $\longrightarrow \mathrm{h}=14.0 \mathrm{~m} ; \mathrm{T}=11.6 \mathrm{~m} ; \mathrm{TA}-\mathrm{TV}=0.0 \mathrm{~m}$ $\boldsymbol{- A}-\mathrm{h}=13.3 \mathrm{~m} ; \mathrm{T}=11.6 \mathrm{~m} ; \mathrm{TA}-\mathrm{TV}=0.0 \mathrm{~m}$ $\square-h=18.0 \mathrm{~m} ; \mathrm{T}=15.0 \mathrm{~m} ; \mathrm{TA}-\mathrm{TV}=2.0 \mathrm{~m}$ 一 $\boxminus-\mathrm{h}=17.0 \mathrm{~m} ; \mathrm{T}=15.0 \mathrm{~m} ; \mathrm{TA}-\mathrm{TV}=2.0 \mathrm{~m}$

Fig. 4. Ship model D: maximum squat [3].

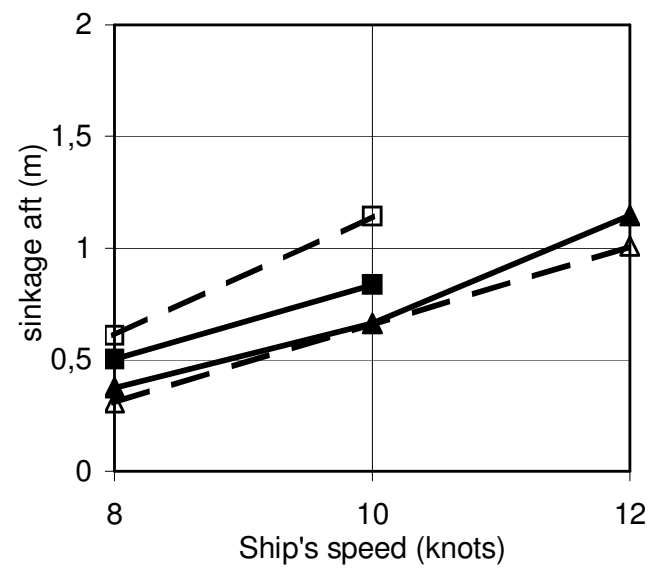

$\longrightarrow \mathrm{D} ; \mathrm{h}=13.3 \mathrm{~m} ; \mathrm{T}=11.6 \mathrm{~m}$ (sinkage aft)

$\longrightarrow E ; h=13.3 \mathrm{~m} ; \mathrm{T}=11.6 \mathrm{~m}$ (sinkage fore)

$-\Delta-F ; h=13.6 \mathrm{~m} ; \mathrm{T}=11.6 \mathrm{~m}$ (sinkage aft)

$\longrightarrow-G ; h=13.6 \mathrm{~m} ; \mathrm{T}=11.6 \mathrm{~m}$ (sinkage fore)

Fig. 5. Squat: comparison between ship models [3].
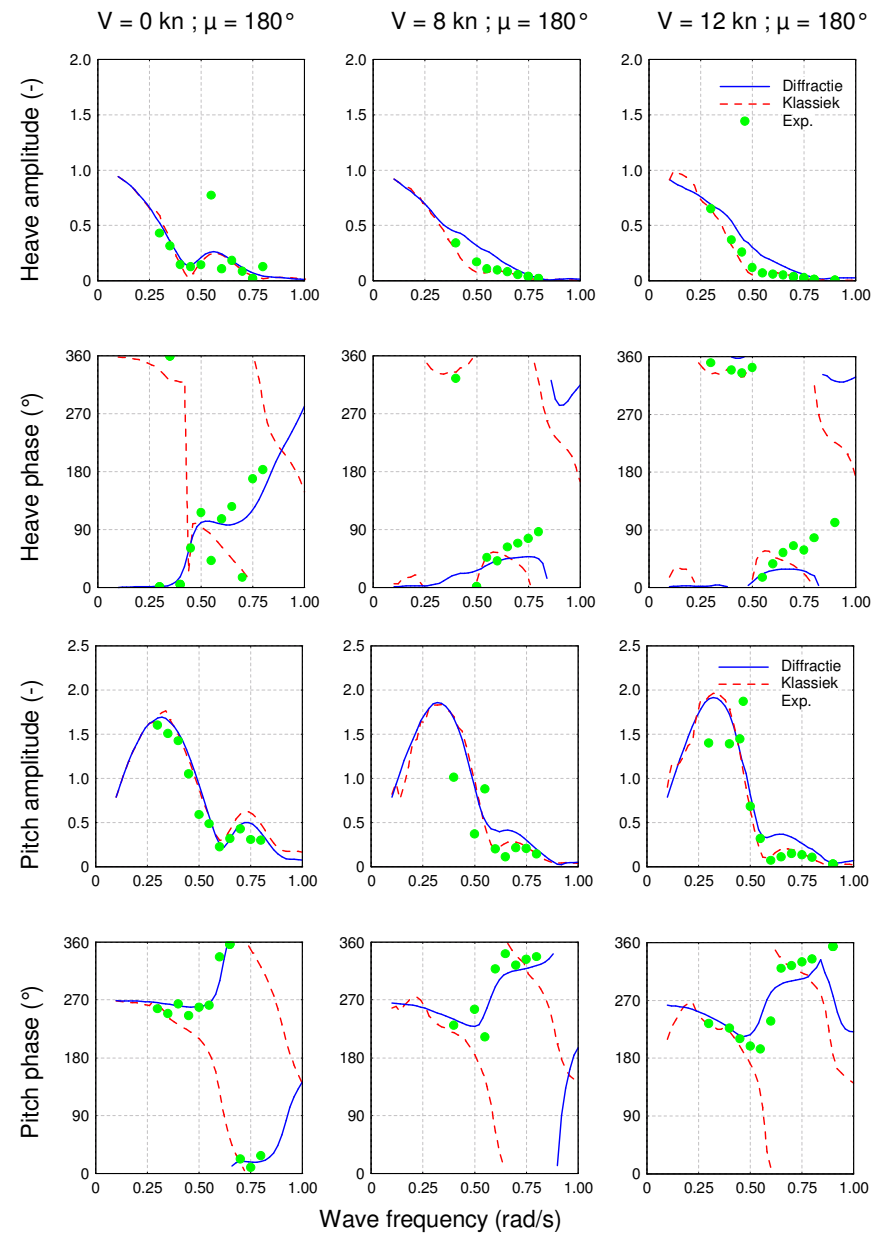

Fig. 6. Panamax container vessel F, condition FA. Heave and pitch motions in head waves: comparison between model tests $(\bullet)$ and SEAWAY results computed with 2D diffraction method (-) and classical strip theory (- - ), [6].

\section{Vertical Ship Response to Waves}

For a number of draft - water depth combinations for each ship in Fig. 2, the response functions for heave, pitch and roll are stored in the ship database for a range of forward ship speeds; the roll characteristics are defined for a number of metacentric heights. The response functions are formulated under tabular form as a function of wave frequency and wave angle of incidence.

The response functions are derived partly from the results of tests in regular waves, partly from numerical calculations. The dimensions of the Towing tank for manoeuvres in shallow water only allows the execution of model tests with angles of incidence in the ranges $[-10 \mathrm{deg} ; 10 \mathrm{deg}$ (following waves) and $[170 \mathrm{deg} ; 190 \mathrm{deg}$ ] (head waves). Tests with higher angles of incidence can only be carried out at zero speed.

Therefore, computer computations have been used to increase the database by including motions for larger wave angles. Seaway, a strip-theory based seakeeping program 
developed by Journée [4], appeared to generate results with acceptable accuracy in comparison with experimental data. As an illustration, Fig. 6 compares the frequency characteristics for heave and pitch of ship model $\mathrm{F}$ in head waves.

The program Seaway allows the computation of the diffraction component of wave induced forces and moments by two different methods, either by a classical strip theory approximation or by a two dimensional diffraction method. The first method derives the 2-D diffraction force on each strip from the hydrodynamic mass and damping of the local ship section and the velocity and acceleration of the water particles. The second method obtains the amplitude of the 2-D wave force from the diffracted energy of the incoming wave; the phase shifts are approximated by theories that actually only are valid for low and high frequency head and beam waves. For intermediate frequencies, a pragmatic solution is applied. Both calculation methods are described in detail in [4].

The 2-D diffraction method generally yields slightly better results in deep water [5]. In shallow water, however, both methods lead to similar results, see Fig. 7-8 [6]. However, the database is created by following the classical strip theory approach, because for wave frequencies above $0.6 \mathrm{rad} / \mathrm{s}-\mathrm{a}$ dominant range in the southern North Sea - this method leads to a better match of the results when compared with model trial results.

A selection of experimental results has also been compared to the output of a 3-D boundary element method (AQUA+). In head waves (Fig. 7), the BEM results are very good for the pitch motion, even for wave lengths that are relatively small compared to the ship length. For heave, the BEM results appear to be superior to the (ordinary) strip theory. Phase angle results are subject to larger deviations, especially when the response is small. In following waves (Fig. 8), the BEM offers an advantage, while pitch motions are in general overestimated by both the BEM and the ordinary strip theory. The roll motion appears to be predicted well by the strip theory, but is problematic for the BEM.

\section{PROBABILISTIC CONSIDERATIONS}

\section{Calculation scheme for probability of bottom touch}

The following steps are executed consecutively to calculate the probability of bottom touch during a particular voyage.

- A ship is selected in the database, by direct input .

- Based on departure time and ship's speed, the water depth and current vector along the trajectory are calculated, taking account of the local bottom depth and the tidal data. The trajectory is divided into sub-trajectories $(\mathrm{j}=1, \ldots, \mathrm{n})$ in which the (local and instantaneous) water depth is approximately constant.

- For each sub-trajectory, four combinations water depth draft - speed are selected in the database which give the best approximations for the actual condition. A weight factor is attributed to each selected combination.
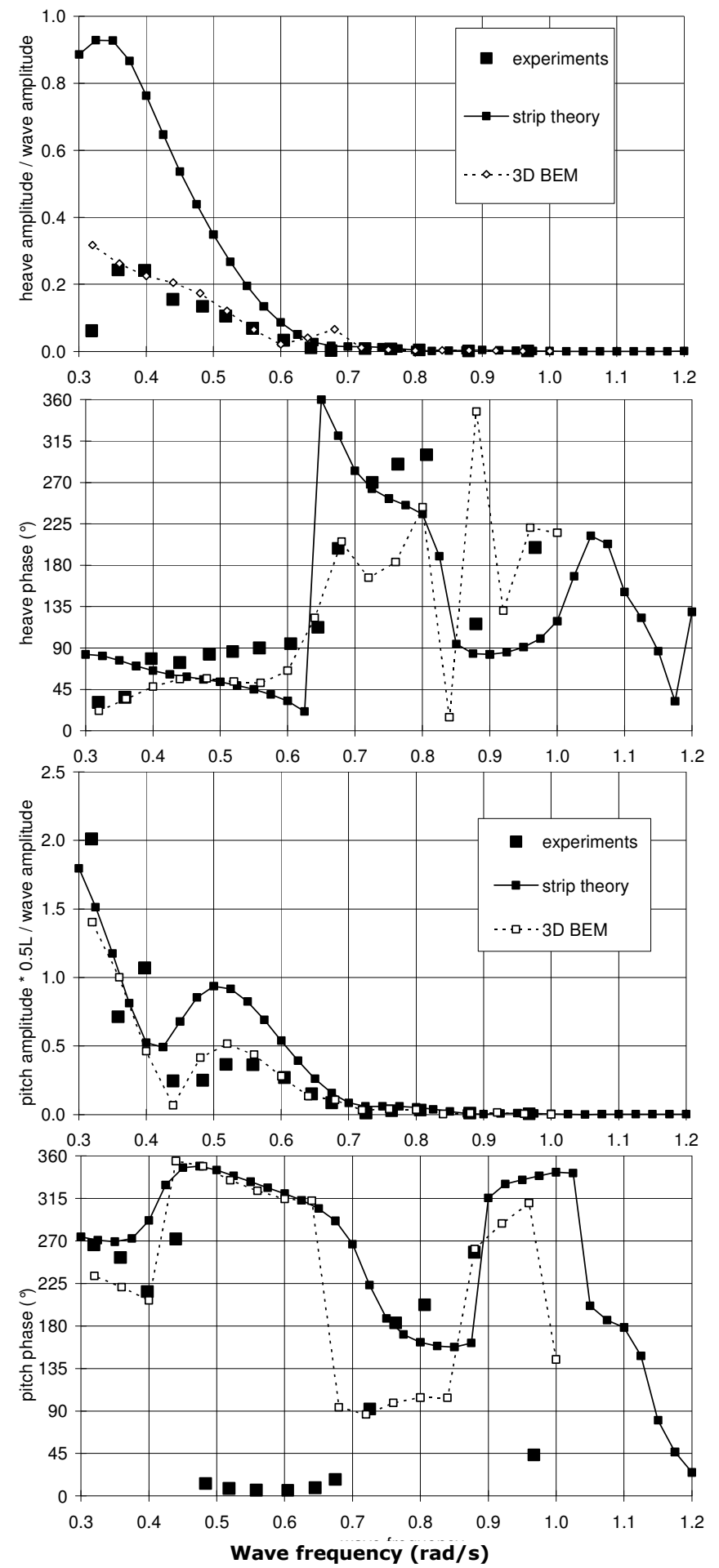

Fig. 7. Container vessel D, condition DA. Heave and pitch motions in head waves ( $\mathrm{V}=12$ knots, $\mu=180 \mathrm{deg}$ ): comparison between model tests and results of 3D-BEM and strip theory computations.

- Sinkage and trim are calculated for each sub-trajectory, taking account of the ship's speed through the water. This 
allows computation of the sinkage $\overline{Z_{\ell}}$ of a number of socalled critical points on the ship hull. These points are predefined as the positions on the hull that are most likely to experience bottom touch, see Fig. 9.

- For each sub-trajectory, the wave data (spectral density $S_{\zeta}(\omega)$, average angle of propagation, standard deviation of this angle) for the reference location are introduced and transformed into a table $S_{\zeta}(\omega, \mu)$ of the spectral density of the irregular seaway as a function of angle of incidence and pulsation.

- Based on the motion characteristics for the four selected combinations $\left(T_{k}, h_{k}, V_{k}\right)$, the spectral density table $S_{\zeta}(\omega, \mu)$ and the experimentally determined correction factors for response in irregular seaways, weighted average amplitude and phase characteristics for heave, pitch and roll are computed. This allows the computation of the amplitude characteristic of the vertical motion of each critical point $\mathrm{Y}_{\mathrm{Z}_{\ell} \zeta}(\omega ; \mu)(\ell=1, \ldots, \mathrm{N})$.

- The spectral density function of the vertical response of critical point $\ell$ can be computed as

$$
\mathrm{S}_{\mathrm{Z}_{\ell}}(\omega ; \mu)=\mathrm{S}_{\zeta}(\omega ; \mu) \cdot \mathrm{Y}_{\mathrm{Z}_{\ell} \zeta}^{2}(\omega ; \mu)
$$

which allows computation of:

$$
\begin{gathered}
\mathrm{m}_{0, \mathrm{Z}_{\ell}}=\int_{0}^{2 \pi} \int_{0}^{+\infty} \mathrm{s}_{\mathrm{Z}_{\ell}}(\omega ; \mu) \mathrm{d} \omega \mathrm{d} \mu=16 \mathrm{Z}_{\mathrm{s}, \ell}^{2} \\
\mathrm{~m}_{2, \mathrm{Z}_{\ell}}=\int_{0}^{2 \pi} \int_{0}^{+\infty} \mathrm{S}_{\mathrm{Z}_{\ell}}(\omega ; \mu) \omega^{2} \mathrm{~d} \omega \mathrm{d} \mu
\end{gathered}
$$

$\mathrm{Z}_{\mathrm{s}, \ell}$ being the significant value of the vertical wave-induced peak-to-peak motion of critical point $\ell$, comparable to the significant wave height.

The net under keel clearance for point $\ell$ in sub-trajectory $\mathrm{j}$ is denoted $\mathrm{UKC}_{\mathrm{j}, \ell}$ :

$$
\mathrm{UKC}_{\mathrm{j}, \ell}=\mathrm{h}_{\mathrm{j}}-\mathrm{T}_{\ell}-\overline{\mathrm{Z}_{\ell}}
$$

As the peak-to-peak values of the vertical wave-induced motion of critical point $\ell$ are assumed to follow a Rayleigh distribution:

$$
\mathrm{p}_{\mathrm{R}}\left(\mathrm{Z}_{\ell} ; \mathrm{Z}_{\mathrm{s}, \ell}\right)=\frac{16}{\mathrm{Z}_{\mathrm{s}, \ell}^{2}} \mathrm{Z}_{\ell} \mathrm{e}^{-8\left(\frac{\mathrm{z}_{\ell}}{\mathrm{z}_{\mathrm{s}, \ell}}\right)^{2}}
$$

the probability of bottom touch of critical point $\ell$ for one oscillatory cycle is given by:
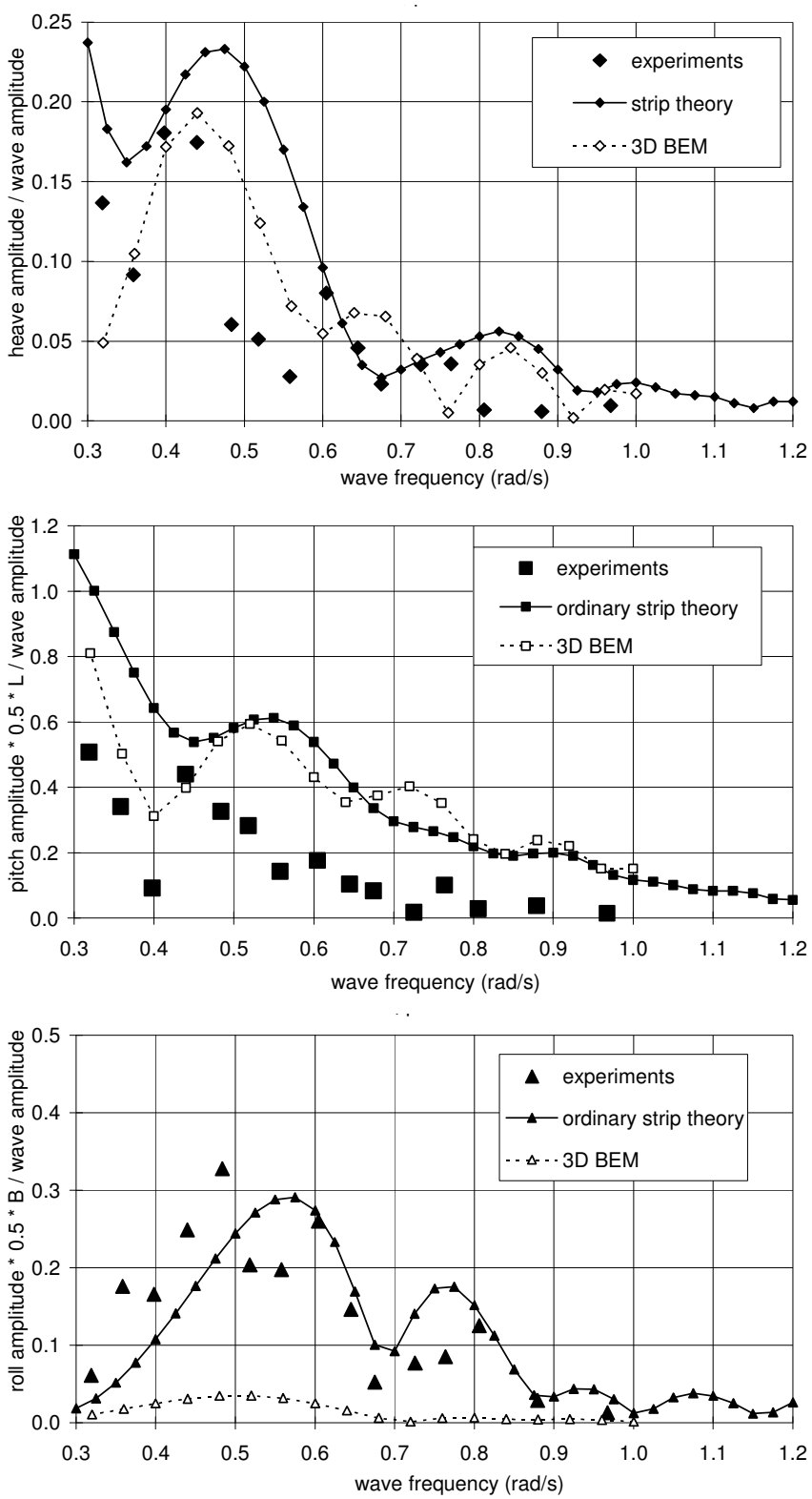

Fig. 8. Container vessel D, condition DA. Heave, pitch and roll motions in following waves $(\mathrm{V}=12 \mathrm{knots}, \mu=10 \mathrm{deg})$ : model tests versus results of 3D-BEM and strip theory computations.

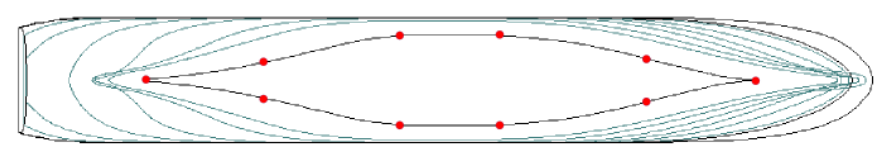

Fig. 9. Illustration of critical point positions 
departure time referred to high tide at Zeebrugge $(\mathrm{h})$

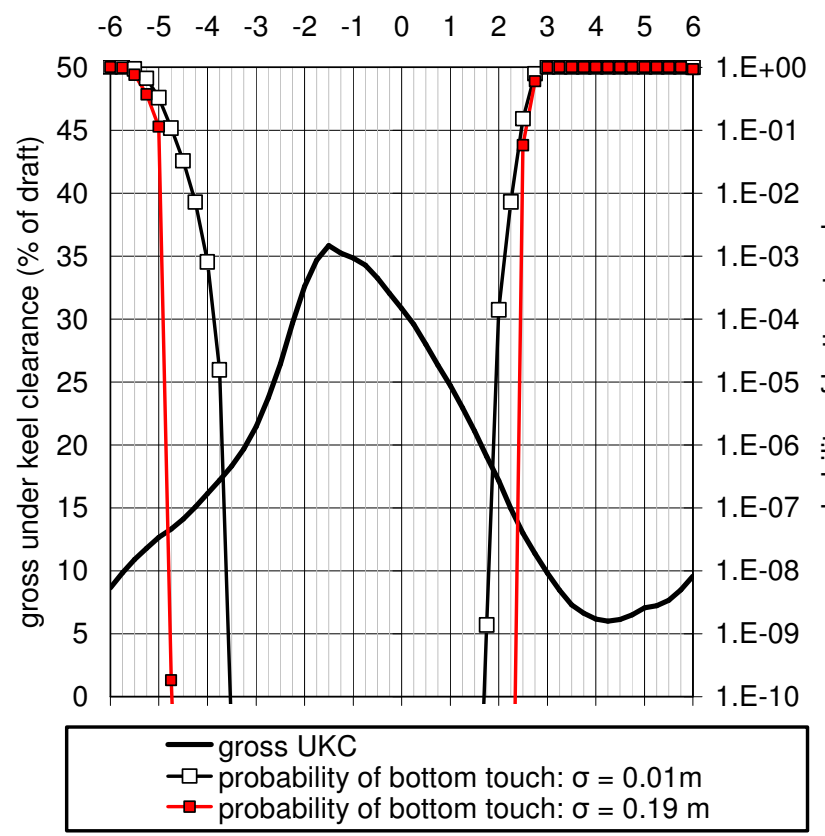

Fig. 10. Arrival of a $15 \mathrm{~m}$ draft container vessel at Zeebrugge (fictitious example): influence of standard deviation of tide prediction.

$$
\mathrm{P}_{\mathrm{j}, \ell}^{(1)}=\mathrm{P}\left[\mathrm{Z}_{\ell}>\mathrm{UKC}_{\mathrm{j}, \ell}\right]=\mathrm{e}^{-\frac{\mathrm{UKC}_{\mathrm{j}, \ell}^{2}}{2 \mathrm{~m}_{0, \mathrm{Z}_{\ell}}}}=\mathrm{e}^{-8\left(\frac{\mathrm{UKC}_{\mathrm{j}, \ell}}{\mathrm{Z}_{\mathrm{s}, \ell}}\right)^{2}}
$$

The probability of bottom touch of critical point $\ell$ during the passage of the ship in sub-trajectory $j$ with length $L_{j}$ at speed $V$ can be expressed by:

$$
\mathrm{P}_{\mathrm{j}, \ell}=\frac{1}{2 \pi} \sqrt{\frac{\mathrm{m}_{2, \mathrm{Z}_{\ell}}}{\mathrm{m}_{0, \mathrm{Z}_{\ell}}}} \frac{\mathrm{L}_{\mathrm{j}}}{\mathrm{V}} \mathrm{P}_{\mathrm{j}, \ell}^{(1)}
$$

$P_{j} \equiv \max \left(P_{j}, \ell\right)$ can be considered as the probability of bottom touch in sub-trajectory $\mathrm{j}$. The probability $\mathrm{P}$ of bottom touch in full trajectory can be computed as:

$$
P=1-\prod_{j=1}^{N}\left(1-P_{j}\right)
$$

\section{Effect of uncertainty of net under keel clearance}

The calculation above is valid if the net under keel clearance $\mathrm{UKC}_{\mathrm{j}, \ell}$ is exactly known. In reality, this value is subject to uncertainty, due to uncertainty of the bottom level, the still water draft, the tidal level, the squat estimation. If a normal distribution of this net under keel clearance is assumed with standard deviation $\sigma_{\mathrm{Z} \ell},(9)$ can be calculated as follows:

$$
\begin{aligned}
\mathrm{P}_{1} & =\int_{0}^{\infty} \mathrm{p}_{\mathrm{R}}\left(\mathrm{z} ; \mathrm{Z}_{\mathrm{s}, \ell}\right) \mathrm{P}_{\mathrm{G}}\left(\mathrm{z} ; \mathrm{UKC}_{\mathrm{j}, \ell} ; \sigma_{\mathrm{Z}_{\ell}}\right) \mathrm{dz} \\
& =\int_{0}^{\infty} \frac{16}{\mathrm{Z}_{\mathrm{S}, \ell}^{2}} \mathrm{z}^{-8 \frac{\mathrm{z}^{2}}{\mathrm{Z}_{\mathrm{S}, \ell}^{2}}} \mathrm{dz} \int_{-\infty}^{\mathrm{z}} \frac{1}{\sqrt{2 \pi} \sigma_{\mathrm{Z}_{\ell}}} \mathrm{e}^{-\frac{\left(\mathrm{x}-\mathrm{UKC}_{\mathrm{j}, \ell}\right)^{2}}{2 \sigma_{\mathrm{Z}_{\ell}}}} \mathrm{dx}
\end{aligned}
$$

The importance of a reliable tide forecast is illustrated in Fig. 10. For a container carrier with $15.0 \mathrm{~m}$ draft, the window based on a $10^{-4}$ probability of bottom touch appears to decrease with 1.5 hours if the standard deviation on the tide prediction increases from $0.01 \mathrm{~m}$ to $0.19 \mathrm{~m}$. It should be emphasized that an accurate tide prediction is not only of importance in the frame of a probabilistic approach philosophy, but also if the admittance policy is based on minimum values for the gross under keel clearance.

\section{Effect of uncertainty of wave forecast}

The calculation scheme described above is valid for a given wave climate. If the wave input is based on forecasts, however, the uncertainty on the prediction should be taken into account.

If the significant wave height $\mathrm{H}_{\mathrm{s}}$ is predicted with an uncertainty expressed by a standard deviation $\sigma_{\mathrm{Hs}}$, it can be assumed that the significant wave-induced motion $Z_{\mathrm{s}, \ell}$ has a normal distribution with standard deviation $\sigma_{\mathrm{Zs}, \ell}$. The peak-topeak values of the vertical wave-induced motion of a critical point $\ell$ no longer follows a Rayleigh distribution (10), but a Rayleigh based distribution with a Gaussian distribution of the variance:

$$
\begin{aligned}
\mathrm{p}_{\mathrm{RG}}\left(\mathrm{Z}_{\ell} ; \mathrm{Z}_{\mathrm{s}, \ell} ; \sigma_{\mathrm{Zs}, \ell}\right) & =\int_{-\infty}^{+\infty} \mathrm{p}_{\mathrm{G}}\left(\mathrm{Z}_{\mathrm{S}} ; \mathrm{Z}_{\mathrm{s}, \ell} ; \sigma_{\mathrm{Zs}, \ell}\right) \frac{16}{\mathrm{Z}_{\mathrm{S}}^{2}} \mathrm{Z}_{\ell} \mathrm{e}^{-8 \frac{\mathrm{Z}_{\ell}^{2}}{\mathrm{Z}_{\mathrm{S}}^{2}}} \mathrm{dZ} \mathrm{Z}_{\mathrm{S}} \\
& \approx \frac{\int_{0}^{+\infty} \mathrm{p}_{\mathrm{G}}\left(\mathrm{Z}_{\mathrm{S}} ; \mathrm{Z}_{\mathrm{s}, \ell} ; \sigma_{\mathrm{Zs}, \ell}\right) \frac{16}{\mathrm{Z}_{\mathrm{S}}^{2}} \mathrm{Z}_{\ell} \mathrm{e}^{-8 \frac{\mathrm{Z}_{\ell}{ }^{2}}{\mathrm{Z}_{\mathrm{S}}^{2}}} \mathrm{dZ} \mathrm{Z}_{\mathrm{S}}}{\int_{0}^{+\infty} \mathrm{p}_{\mathrm{G}}\left(\mathrm{Z}_{\mathrm{S}} ; \mathrm{Z}_{\mathrm{s}, \ell} ; \sigma_{\mathrm{Zs}, \ell}\right) \mathrm{d} \mathrm{Z}_{\mathrm{S}}}
\end{aligned}
$$

taking account that negative values for the significant value of the vertical motion are physically meaningless.

By calculating the probability of bottom touch in this way, not only account can be taken of the quality of the wave forecasts, but also uncertainties of ship characteristics can be dealt with. As a matter of fact, the RAOs for heave, pitch and roll not only depend on the main dimensions of the ship, but also on parameters that depend on the weight distribution, such as the moments of inertia and the metacentric height. A spreading of $5 \%$ appears to be sufficient to take account of variations of the longitudinal moment of inertia, but the effect of GM variations may be 10 to $20 \%$. Although stability data should be available on board, in practice it is extremely difficult for waterway authorities and pilots to obtain such information. 


\section{EXAMPLE}

A (fictitious) example of the output of ProToel is given in Table 3; it concerns a container carrier with $14.6 \mathrm{~m}$ draft leaving the harbor of Zeebrugge. Following a deterministic approach based on gross under keel clearance, the tidal windows at 22:33 and closes at 06:18; however, between 00:03 and 03:33, and after 05:48 no traffic is possible due to the tidal currents. In the example, the fluid mud layer that covers the solid bottom in the outer harbor of Zeebrugge, does not influence the tidal window, as the other criteria are more limiting.

If a probabilistic approach were followed, the tidal window would already open at 21:18 and close at 07:18. However, the restrictions due to current are still valid, so that the practical window would open earlier, but close at the same time. Nevertheless, it should be borne in mind that the criterion to maintain a $10 \%$ gross under keel clearance referred to the nautical bottom is not related to the risk of bottom touch, but to maneuverability. This implies that the net increase of the tidal window would be 30 minutes, which is still valuable in the frame of an optimization process of the shipping traffic. The probabilistic approach would imply the $12.5 \%$ UKC criterion in the access channel Pas van het Zand to be overruled.

\section{FUTURE DEVELOPMENTS}

At present, a research project is carried out by the Maritime Technology Division of Ghent University by order of Flanders Hydraulics Research. The purpose of this project is to:

- $\quad$ organize the input management of ProToel by coordinating the inflow of hydro-meteo data, and transform and complete these data if required;

- install the program on behalf of the main potential users of ProToel, i.e. the Flemish Pilotage and the Shipping Assistance Department of the Flemish Government;

- improve the input data by selection of data sources and performing a quality control by comparing ProToel advice with practice;

- $\quad$ extending the database by means of model tests with ship model W.

Although the present deterministic, UKC based admittance policy will be maintained on short term, it is the purpose to develop ProToel to a main tool for planning the shipping traffic to Zeebrugge. As probabilistic and deterministic windows will be generated simultaneously, a permanent evaluation of and comparison between both methods will be possible; in case satisfactory results are obtained with the probabilistic approach, the introduction of the latter could be taken into consideration.

\section{CONCLUSIONS}

A planning tool has been developed for advising pilots and waterways authorities on optimal use of the approach channels to the Belgian harbors. The tool is based on an acceptable probability of bottom touch, in combination with other criteria concerning minimum gross under keel clearances, penetration into fluid mud layers and acceptable cross currents. Although the probabilistic aspects are mainly introduced due to response of the vessels to the local wave climate, other causes of uncertainty, such as scatter on the ship's draft, unknown ship characteristics, bottom level fluctuations, tidal prediction errors, uncertainties of wave forecasts, can be included in the calculation scheme as well.

\section{ACKNOWLEDGMENTS}

The present and former research projects for the realization of the probabilistic approach policy are financed and supported by the Flemish Government (Flanders Hydraulics Research, Flemish Hydrography, Shipping Assistance, Flemish Pilotage).

\section{REFERENCES}

[1] Vantorre, M.; Laforce, E.; Dumon, G. and Wackenier, W, 2002, "Development of a probabilistic admittance policy for the Flemish harbours", 30th PIANC Congress, Sydney.

[2] Vantorre, M. and Dumon, G., 2004, "Model test based requirements for the under keel clearance in the access channels to the Flemish harbours", 2nd Squat Workshop "Aspects of Under Keel Clearance in Analysis and Application", Elsfleth.

[3] U.S. Army Corps of Engineers (USACE). 2004, "Engineering and Design: Hydraulic Design Guidance for Deep-draft Navigation Projects", Engineer Manual 1110-21613, Headquarters, Washington, DC.

[4] Journée, J. and Adegeest, L., 2003. "Theoretical Manual of SEAWAY for Windows". Laboratory of Ship Hydromechanics, Technical University Delft, Report 1370.

[5] Journée, J., 2001, "Verification and Validation of Ship Motions Program SEAWAY", Laboratory of Ship Hydromechanics, Technical University Delft, Report 1213a.

[6] Vantorre, M. and Journée, J.M.J., 2003, "Validatie van scheepsbewegingenprogramma SEAWAY met behulp van zeegangsproeven in ondiep water". Colloquium "Numerieke oppervlaktewater modellering, mogelijkheden en beperkingen", Antwerp, Belgium.(in Dutch).

Table 1. Ship models: main dimensions.

\begin{tabular}{|rr|r|r|r|r|r|}
\hline Model & \multicolumn{1}{|c|}{ D } & \multicolumn{1}{|c|}{ E } & \multicolumn{1}{|c|}{ F } & \multicolumn{1}{c|}{ G } & \multicolumn{1}{c|}{ W } \\
\hline Scale & $(-)$ & $1 / 75$ & $1 / 85$ & $1 / 50$ & $1 / 50$ & $1 / 90$ \\
Length over all & $(\mathrm{m})$ & 300.00 & 343.00 & 200.00 & 190.00 & 398.0 \\
Length between & $(\mathrm{m})$ & 291.13 & 325.00 & 190.00 & 180.00 & \\
perpendiculars & & & & & & \\
Breadth, moulded & $(\mathrm{m})$ & 40.25 & 53.00 & 32.00 & 33.00 & 56.40 \\
Maximum draft & $(\mathrm{m})$ & 15.00 & 21.79 & 11.60 & 13.00 & 16.00 \\
Block coefficient at & $(-)$ & 0.60 & 0.85 & 0.60 & 0.85 & \\
max. draft & & & & & & \\
\hline
\end{tabular}


Table 2. Overview of model test conditions.

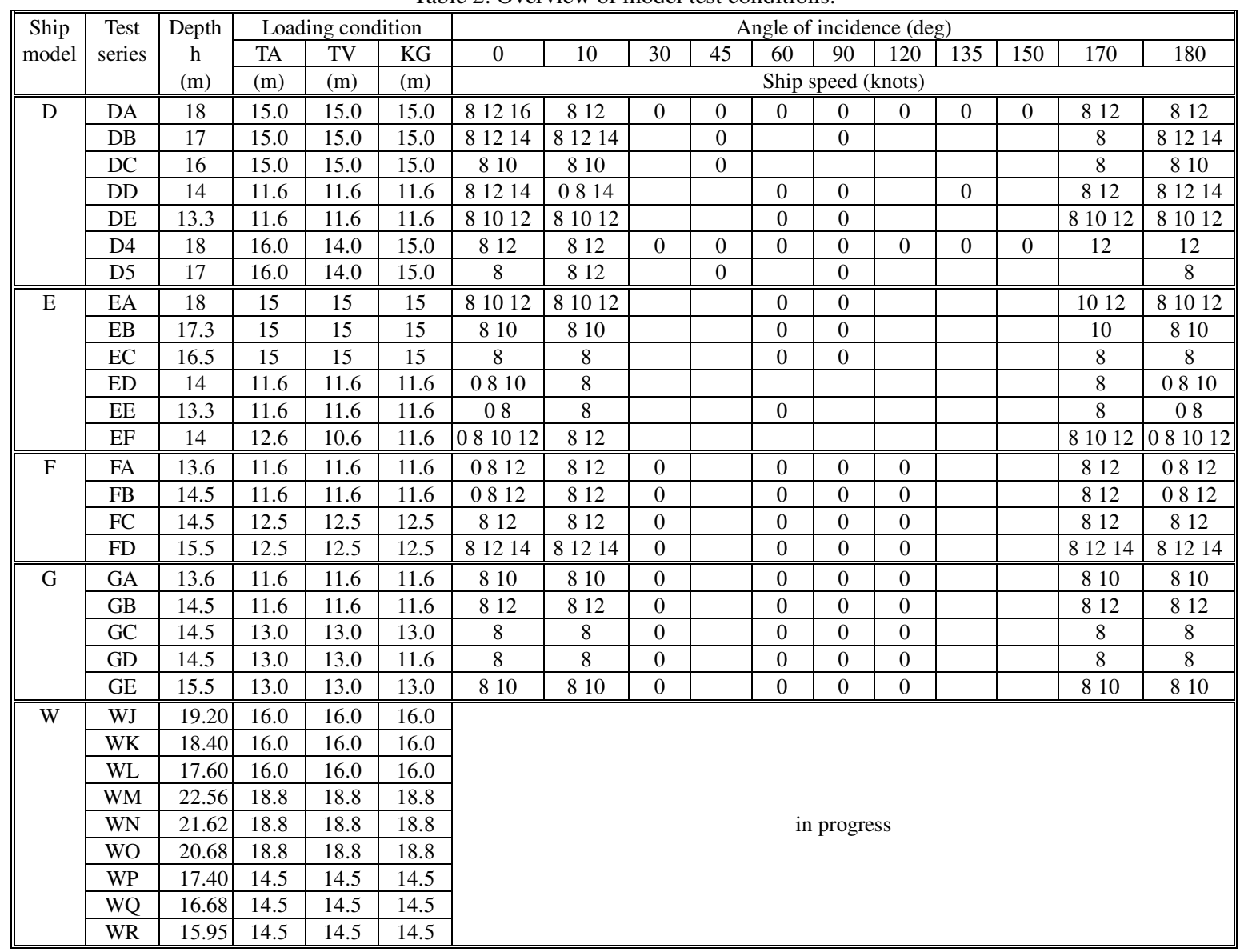

Table 3. ProToel output example.

CONTAINER CARRIER

\section{DRAFT $14.60 \mathrm{~m}$}

\section{Time of departure}

Probability of bottom touch

Scheur - min gross UKC

PvhZ - min bruto UKC (nautical bottom)

PvhZ - max current (knots/10)

Outer harbor - min gross UKC (nautical bottom)

Outer harbor - min gross UKC (top slib)

\section{Time of departure}

Probability of bottom touch

Scheur - min gross UKC

PvhZ - min bruto UKC (nautical bottom)

PvhZ - max current (knots/10)

Outer harbor - min gross UKC (nautical bottom)

Outer harbor - min gross UKC (top slib)

\section{Time of departure}

Probability of bottom touch

Scheur - min gross UKC

PvhZ - min bruto UKC (nautical bottom)

PvhZ - max current (knots/10)

Outer harbor - min gross UKC (nautical bottom)

Outer harbor - min gross UKC (top slib)

\section{Time of departure}

Probability of bottom touch

Scheur - min gross UKC

PvhZ - min bruto UKC (nautical bottom)

PvhZ - max current (knots/10)

Outer harbor - min gross UKC (nautical bottom)

Outer harbor - min gross UKC (top slib)

\section{DEPARTURE FROM ZEEBRUGGE}

\begin{tabular}{|c|c|c|c|c|c|c|c|c|c|c|c|c|c|}
\hline CRIT & 2018 & 2033 & 2048 & 2103 & 2118 & 2133 & 2148 & 2203 & 2218 & 2233 & 2248 & 2303 & 2318 \\
\hline 1.E-04 & 5.E-02 & 2.E-02 & 4.E-03 & 4.E-04 & 2.E-05 & 1.E-07 & $5 . E-10$ & 2.E-12 & 6.E-15 & 1.E-20 & 1.E-20 & 1.E-20 & 1.E-20 \\
\hline 15.0 & 11.2 & 11.8 & 12.5 & 13.3 & 13.8 & 14.6 & 15.3 & 16.2 & 17.0 & 17.9 & 19.0 & 20.2 & 21.5 \\
\hline 12.5 & 7.6 & 7.7 & 8.2 & 8.9 & 9.8 & 10.5 & 11.2 & 11.8 & 12.4 & 13.1 & 13.9 & 14.7 & 15.7 \\
\hline 20.0 & 22.0 & 16.3 & 16.2 & 15.9 & 15.6 & 14.8 & 13.7 & 12.5 & 11.4 & 9.5 & 6.8 & 7.6 & 10.5 \\
\hline 10.0 & 7.5 & 7.0 & 6.8 & 7.0 & 7.6 & 8.4 & 9.3 & 10.0 & 10.7 & 11.2 & 11.8 & 12.5 & 13.4 \\
\hline-7.0 & -7.2 & -7.6 & -7.6 & -7.4 & -6.8 & -6.0 & -5.1 & -4.4 & -3.7 & -3.2 & -2.5 & -1.8 & -1.0 \\
\hline CRIT & 2318 & 2333 & 2348 & 0003 & 0018 & 0033 & 0048 & 0103 & 0118 & 0133 & 0148 & 0203 & 0218 \\
\hline 1.E-04 & 1.E-20 & 1.E-20 & 1.E-20 & 1.E-20 & 1.E-20 & 1.E-20 & 1.E-20 & 1.E-20 & 1.E-20 & 1.E-20 & 1.E-20 & 1.E-20 & 1.E-20 \\
\hline 15.0 & 21.5 & 23.1 & 25.0 & 27.3 & 29.8 & 32.0 & 33.9 & 35.3 & 36.0 & 36.3 & 36.3 & 36.1 & 35.7 \\
\hline 12.5 & 15.7 & 16.8 & 18.1 & 19.6 & 21.4 & 23.6 & 26.0 & 28.4 & 30.5 & 32.1 & 33.0 & 33.5 & 33.5 \\
\hline 20.0 & 10.5 & 14.1 & 17.8 & 21.6 & 23.2 & 21.7 & 29.5 & 35.2 & 38.2 & 38.9 & 39.0 & 38.0 & 34.4 \\
\hline 10.0 & 13.4 & 14.2 & 15.3 & 16.5 & 17.8 & 19.4 & 21.5 & 23.7 & 26.3 & 28.4 & 30.4 & 32.0 & 32.6 \\
\hline-7.0 & -1.0 & -0.2 & 0.9 & 2.1 & 3.4 & 5.0 & 7.1 & 9.4 & 11.9 & 14.0 & 16.0 & 17.6 & 18.2 \\
\hline CRIT & 0233 & 0248 & 0303 & 0318 & 0333 & 0348 & 0403 & 0418 & 0433 & 0448 & 0503 & 0518 & 0533 \\
\hline 1.E-04 & 1.E-20 & 1.E-20 & 1.E-20 & 1.E-20 & 1.E-20 & 1.E-20 & 1.E-20 & 1.E-20 & 1.E-20 & 1.E-20 & 1.E-20 & 1.E-20 & 1.E-20 \\
\hline 15.0 & 35.0 & 34.3 & 33.1 & 31.7 & 30.2 & 28.7 & 27.3 & 25.7 & 24.2 & 22.7 & 21.4 & 20.1 & 18.7 \\
\hline 12.5 & 33.1 & 32.7 & 31.9 & 31.2 & 30.5 & 29.6 & 28.6 & 27.4 & 26.3 & 25.1 & 23.7 & 22.3 & 20.8 \\
\hline 20.0 & 30.6 & 28.0 & 23.0 & 22.4 & 21.1 & 18.0 & 17.6 & 14.5 & 10.6 & 7.4 & 8.9 & 12.2 & 15.5 \\
\hline 10.0 & 33.1 & 32.7 & 32.4 & 31.8 & 30.9 & 30.4 & 29.3 & 28.4 & 27.5 & 26.0 & 25.0 & 23.6 & 22.1 \\
\hline-7.0 & 18.5 & 18.2 & 17.8 & 17.0 & 16.3 & 15.6 & 14.4 & 13.7 & 12.4 & 11.1 & 10.0 & 8.4 & 7.1 \\
\hline CRIT & 0548 & 0603 & 0618 & 0633 & 0648 & 0703 & 0718 & 0733 & 0748 & 0803 & & & \\
\hline 1.E-04 & 1.E-20 & 1.E-20 & 1.E-20 & 2.E-12 & 4.E-10 & 4.E-07 & 2.E-05 & 2.E-03 & 2.E-01 & I. E+00 & & & \\
\hline 15.0 & 17.5 & 16.4 & 15.4 & 14.2 & 13.0 & 12.0 & 11.0 & 10.2 & 9.4 & 8.7 & & & \\
\hline 12.5 & 19.3 & 17.7 & 16.0 & 14.5 & 12.9 & 11.6 & 10.1 & 9.0 & 8.0 & 7.0 & & & \\
\hline 20.0 & 19.1 & 22.7 & 25.3 & 26.0 & 26.0 & 22.8 & 21.5 & 21.0 & 21.0 & 20.8 & & & \\
\hline 10.0 & 20.7 & 19.0 & 17.4 & 16.0 & 14.2 & 12.9 & 11.4 & 10.1 & 8.8 & 7.5 & & & \\
\hline-7.0 & 5.5 & 3.8 & 2.4 & 0.8 & -0.9 & -2.2 & -3.7 & -4.9 & -6.3 & -7.3 & & & \\
\hline
\end{tabular}

